\title{
PHOSPHORUS MODELS FOR EUTROPHIC LAKES
}

\author{
Wu Seng Lung*, Raymond P. Canale and Paul L. Freedman \\ University of Michigan, Ann Arbor, MI 48104, U.S.A.
}

(Received 3 June 1976)

\begin{abstract}
A model is developed for a highly eutrophic lake (White Lake, Michigan) which incorporates both the water and sediment systems and considers two forms of phosphorus-particulate and dissolved. Dynamic interactions of phosphorus between sediments and water are quantified by taking account particulate phosphorus sinking to the sediment-water interface and diffusion of dissolved phosphorus across the interface. Other model mechanisms include vertical eddy diffusion in the water, phosphorus transformation between the particulate form and the dissolved form in both the water and the sediment, diffusion of phosphorus in the interstitial water, and sedimentation in the sediments.

Extensive field data have been used to determine the coefficients and parameters defined in the model formulations. Close agreement between the model calculations and the observed data is obtained, especially for the upper layers of the sediment. Sensitivity analysis for the model further substantiates the model calculations. It is found that two separate forms of phosphorus are necessary to gain detailed insight into the dynamics of phosphorus cycling in White Lake. The model also explains significant releases of phosphorus during anaerobic periods from the sediment to the hypolimnion of White Lake in summer. The general applicability of the model to lakes having different degrees of eutrophication must be determined by an examination and analysis of data from other systems.
\end{abstract}

\section{INTRODUCTION}

This paper describes a multi-component dynamic model developed for phosphorus in eutropic lakes. It is especially applicable for lakes in which sedimentwater interactions are important. Previous models have considered single phosphorus forms (total phosphorus), and have been applied to less eutrophic waters in which sediments play a minor role in regulating the phosphorus cycle. Under certain circumstances, complex phenomena such as release of phosphorus from sediments to overlying waters may complicate the dynamics of phosphorus cycling and require more comprehensive models. The purpose of this paper is to justify, develop, and verify such a model for both particulate and dissolved phosphorus in eutrophic lakes.

It has been hypothesized that in some shallow eutrophic lakes significant amounts of phosphorus may be released from the sediments, resulting in an important source of nutrients for these lakes. This phosphorus regeneration often leads to a seasonal increase of phosphorus concentration in the bottom waters (particularly during the summer months when the dissolved oxygen has been depleted from the hypolimnion). After the fall overturn in such lakes, the regenerated phosphorus can be transported from the hypolimnion to the epilimnion and become available for algal growth. A necessary step for understanding the eutrophication process is to quantify the role of sediments and sediment-water interactions. The proposed model may contribute to such an understanding and may be a useful preliminary water quality management tool.

* Currently with Hydroscience Inc., Westwood, New Jersey, U.S.A.

\section{PREVIOUS MODELS}

Vollenweider (1969) presented a simple eutrophication model which assumed complete mixing and accounts for input and output to lakes with a net loss of phosphorus to the lake bottom sediments. Vollenweider (1975) has additionally concluded that if the rates of natural and manmade phosphorus inputs to lakes and the sedimentation rates are known it is possible to estimate the ultimate system response to the phosphorus loadings. Other similar model approaches can be found in the literature. Dillon \& Rigler (1974) modified Vollenweider's model by calculating the phosphorus retention coefficient from all known inputs and outflows in order to eliminate the need to measure the sedimentation rate. This model only considers steady-state conditions, however, and it cannot be used to study the season variations. Since few lakes approach steady-state conditions but rather are seasonally dynamic this modeling approach has limitations.

The completely mixed system assumption in the above models is probably violated in most lakes, particularly during summer stratification. At this time mixing between epilimnion and hypolimnion is limited by the thermocline. Disregarding the vertical variation of phosphorus concentration may produce oversimplified and misleading model results. Thus, Imboden (1974) and Snodgrass \& O'Melia (1975) have suggested two-layer lake models and two phosphorus components. Vertical transport of phosphorus by eddy diffusion is considered in these models. Imboden's model also includes phosphorus exchange with sediments. The exchange term, however, must be determined a priori and is described by a constant phosphorus flux at the sediment-water interface. This representation may not approximate the long-term sediment water interactions adequately since the exchange may depend on both conditions in the water and the sediments.

Sediment-water interactions have been modeled dynamically by Lorenzen (1973). The sediment system is coupled with the lake system by releasing sediment nutrients as nutrient input to the water is decreased. Although this model has been applied by Lorenzen et al. (1976) to Lake Washington with encouraging results, it cannot be used to model the seasonal dynamics of phosphorus in lakes. 
Furthermore, the model uses an assumed sediment thickness which may be unrealistic.

The above discussion indicates that previous models have limited ability to accurately describe sediment-water interactions. Thus these models cannot be used to make accurate estimates of water quality in systems such as White Lake where these interactions are important.

\section{PROPOSED MODEL}

The model considered in this work consists of two layers in the water and multi-layers in the sediments. The model was developed for White Lake, a highly eutrophic lake located in southwest Michigan (Chaiken et al., 1973). White Lake is characterized by two basins of about $20 \mathrm{~m}$ maximum depth, a mean depth of $7.9 \mathrm{~m}$, a mean volume of about $8.23 \times 10^{7} \mathrm{~m}^{3}$, and a surface area of $1.04 \times 10^{7} \mathrm{~m}^{2}$
(Fig. 1). One major tributary enters the lake (White River) which has a drainage area of $1000 \mathrm{~km}^{2}$. There is one outlet channel discharging into Lake Michigan. The hydraulic residence time is $1-2$ months during the spring or fall overturn period.

In the model, the lake sediment is divided into 38 layers each $1 \mathrm{~cm}$ thick. This represents the first $38 \mathrm{~cm}$ below the sediment-water interface. This fine vertical resolution of the sediment is justifiable because of the availability of detailed phosphorus profiles from White Lake sediments. Particulate and dissolved phosphorus concentrations are identified as two separate variables in the model to provide additional insight into the phosphorus dynamics. The model structure is shown in Fig. 2. Model mechanisms in the water sediment are similar to those proposed by Stumm \& Leckie (1971) and Imboden (1974).

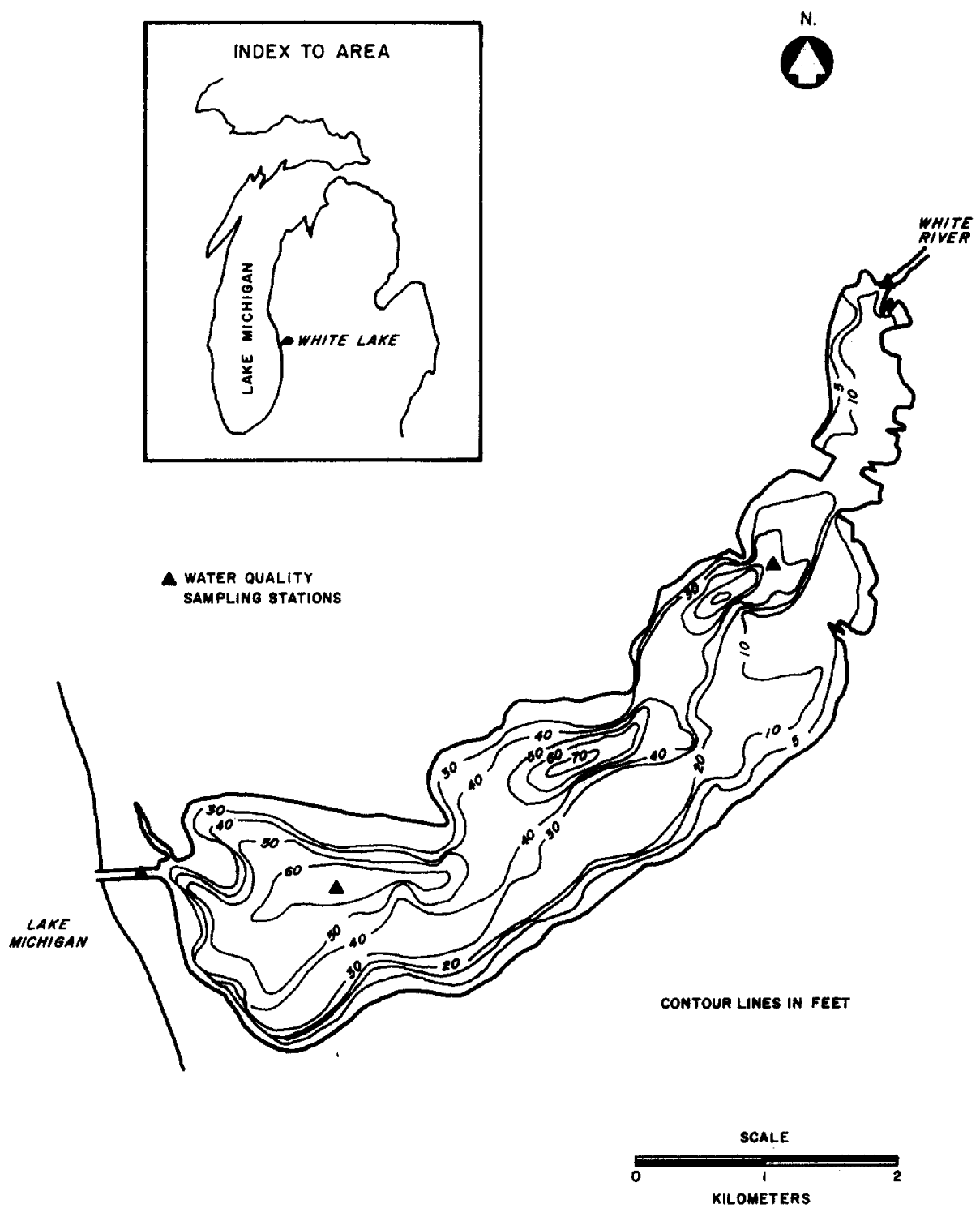

Fig. 1. White Lake 


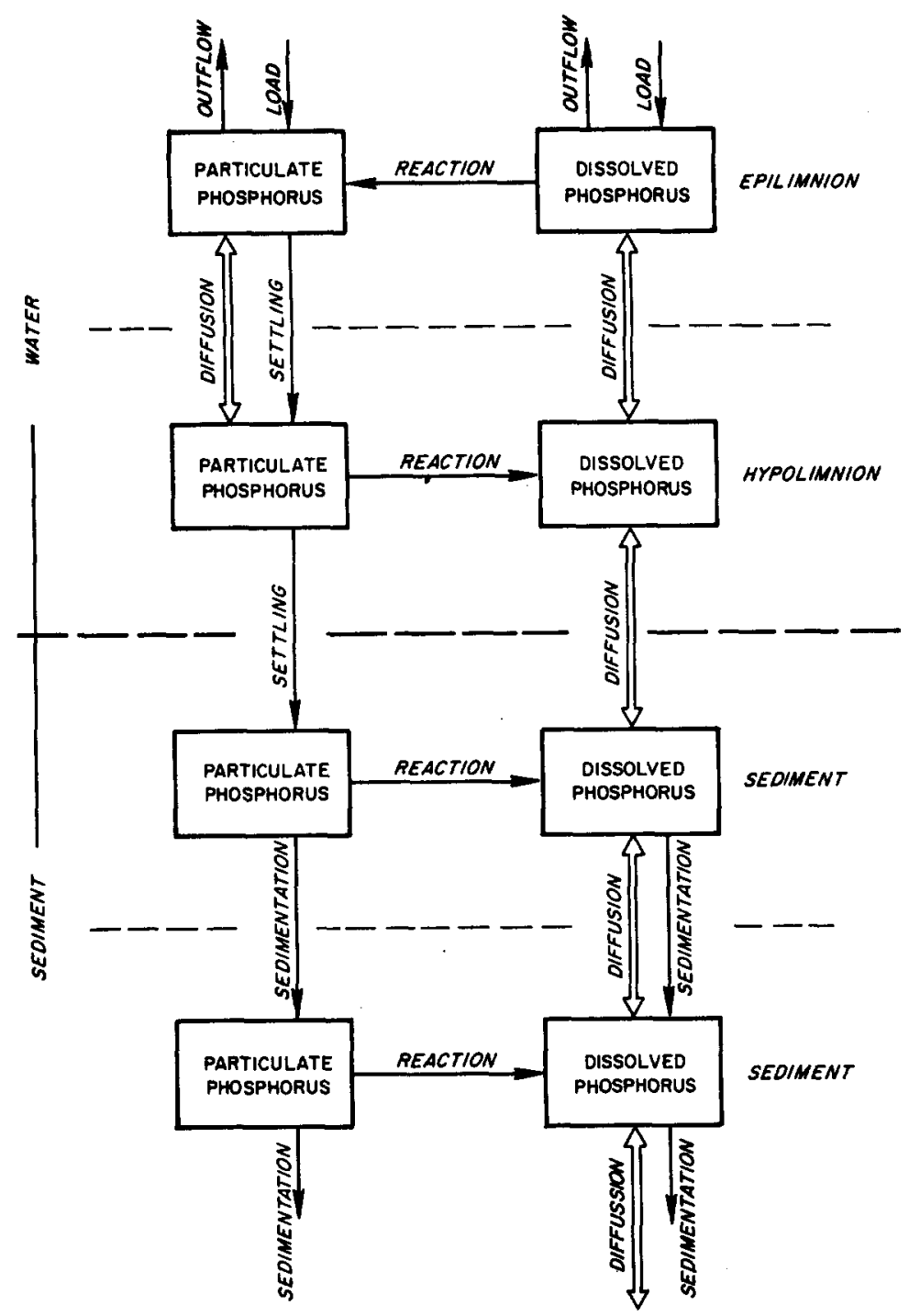

Fig. 2. Proposed phosphorus model for White Lake.

The main mechanism responsible for regeneration of dissolved phosphorus from the sediments is diffusion across the sediment-water interface. This process is a result of concentration differences between the interstitial water of the sediment and the hypolimnion. Although it was generally believed that aerobic release of phosphorus is prohibited by an oxidized microlayer found at the sediment-water interface (Mortimer, 1941, 1942), work by Spear (1970), Sridharan (1970), and Bortleson (1970) has shown that appreciable amounts of inorganic phosphorus is released under aerobic conditions. Since the oxidized microlayer theory has not been fully elucidated, it is questionable whether this barrier is effective when the microzone is unconsolidated and has a high water content (Williams \& Mayers, 1972).* Evidence that phosphorus is released at a slower rate under aerobic conditions than anaerobic conditions has been published (Fillos \& Swanson, 1975; Fillos \& Biswas,

* White Lake, as well as many other highly eutrophic lakes, has such a poorly defined water-sediment interface.
1976). In the model it has been assumed that normal diffusion processes transport phosphorus across the sediment-water interface under both aerobic and anaerobic conditions.

The combined effects of sediment accumulation and compaction cause the sediment-water interface to move upward in reference to a fixed datum. In order to accomodate this moving interface, the space coordinate system in the model has been transformed to move with the interface so that the sediment properties are observed relative to the interface. Thus, a velocity term is introduced in the sediment equations which represents the relative motion of the sediment with respect to the interface. This velocity term is sometimes called a sedimentation rate. For the top layer of sediment, it is the accumulation rate at the interface in $\mathrm{cm} / \mathrm{yr}$. This coordinate transformation approach is acceptable for the sediment system alone. When the sediment system is coupled with the lake system, the volume of the hypolimnion is reduced because of the upward movement of the lake bottom. However, this volume reduction is normally insignifi- 
cant compared with the volume of the lake, and this is the case for White Lake. Therefore, a Lagrangian type coordinate system is used for the sediment and an Eulerian type system is used for the lake system. When the sediment-water interface moves upward, the dissolved phosphorus at the bottom of the lake near the interface is trapped by the sediment system. This amount normally represents a very insignificant loss of phosphorus from the water system.

Because the sediment-water interface moves upward, every layer of the sediment moves according to the Lagragian framework. The sedimentation rate in the lower sediment is smaller than that in the upper sediment because of compaction. It is assumed that the sedimentation rate is inversely proportional to the density of the sediment. This approximation is necessary to insure a steady-state solids mass balance in the sediment.

Model mechanisms in the sediment include diffusion in the interstitial water, sedimentation, and phosphorus transformation from particulate form to dissolved form. The solid particles are not considered to be transported in the sediment through diffusion, although mixing due to biological activity, e.g. organism burrowing, may occur in the first few $\mathrm{cm}$ of the sediment column causing an exchange of solid particles in that region. Sufficient quantitative data to evaluate this mixing rate in White Lake are not available at this time.

In general, there are a number of processes involved with the transformation of phosphorus between the particulate and the dissolved forms. Typical processes include oxidation and breakdown of sedimented organic material both chemical and biological, oxidation and reduction of associated inorganic species, physio-chemical adsorption and precipitation and solution of phosphorus to and from mineral forms (Williams \& Mayer, 1972). A hypothetical phosphorus model proposed by Stumm \& Leckie (1971) describes similar transformations in the sediments. For most of the processes, complete theories and detailed descriptions such as the kinetics of the reactions, are still lacking. It therefore seems justifiable to consider a simpler representation of phosphorus transformations in the sediments. In this model, a first-order kinetic term is adopted to represent the net release of dissolved phosphorus from the phosphorus associated with the solid particles.

The above model mechanisms are transformed into the following differential equations:

(a) Particulate phosphorus in the epilimnion

$$
\begin{array}{cl}
V_{1} \frac{\mathrm{d} C_{P_{1}}}{\mathrm{~d} t}=\frac{K A_{1,2}}{L_{1,2}}\left(C_{P_{2}}-C_{P_{1}}\right) & -v_{s_{1}} C_{P_{1}} A_{1,2} \\
\text { eddy diffusion } & \begin{array}{l}
\text { settling to } \\
\text { hypolimnion }
\end{array}
\end{array}
$$

$$
+\mu_{1} C_{D_{1}} V_{1}+W_{p}-Q C_{P_{1}}
$$

(b) Dissolved phosphorus in the epilimnion

$$
\begin{aligned}
V_{1} \frac{\mathrm{d} C_{D_{1}}}{\mathrm{~d} t}=\frac{K A_{1,2}}{L_{1,2}}\left(C_{D_{2}}-C_{D_{1}}\right) & -\mu_{1} C_{D_{1}} V_{1} \\
\text { eddy diffusion } & \text { reaction } \\
& +W_{D}-Q C_{D_{1}} \\
& \text { loading outflow }
\end{aligned}
$$

(c) Particulate phosphorus in the hypolimnion

$$
\begin{gathered}
V_{2} \frac{\mathrm{d} C_{P_{2}}}{\mathrm{~d} t}=\frac{K A_{1,2}}{L_{1.2}}\left(C_{P_{1}}-C_{P_{2}}\right)+v_{s_{1}} C_{P_{1}} A_{1,2} \\
\text { eddy diffusion } \\
\begin{array}{c}
\text { settling from } \\
\text { epilimnion }
\end{array} \\
-v_{s_{2}} C_{P_{2}} A_{2.3}-\mu_{2} C_{P_{2}} V_{2} \\
\text { settling to reaction } \\
\text { sediment }
\end{gathered}
$$

(d) Dissolved phosphorus in the hypolimnion

$$
\begin{aligned}
& V_{2} \frac{\mathrm{d} C_{D_{2}}}{\mathrm{~d} t}=\frac{K A_{1,2}}{L_{1,2}}\left(C_{D_{1}}-C_{D_{2}}\right) \\
& \quad \text { eddy diffusion } \\
& +\frac{\phi_{0,1} D A_{2,3}}{L_{2,3}}\left(C_{D_{3}}-C_{D_{2}}\right)+\mu_{2} C_{P_{2}} V_{2} \\
& \text { diffusion across reaction } \\
& \text { the interface } \\
& -v_{s s} C_{D_{2}} A_{2.3}
\end{aligned}
$$

loss due to moving boundary

(e) Sedimentation rate at the interface

$$
v_{s s}=C_{P_{2}} * v_{s_{2}}\left(P_{1} \quad * \quad X_{P_{1}}\right)
$$

particulate $P$ sinking density of phosphorus concentration velocity the top content in in the in the sediment solid hypolimnion hypolimnion particles in the top sediment

(f) particulate phosphorus in the nth sediment layer

$$
\begin{gathered}
V_{n} \frac{\mathrm{d} C_{P_{n}}}{\mathrm{~d} t}=v_{s_{n-1}}\left(\alpha_{n-1, n} C_{P_{n-1}}+\beta_{n-1, n} C_{P_{n}}\right) A_{n-1, n} \\
\text { sedimentation from the } \\
\text { upper layer }
\end{gathered}
$$


(g) Dissolved phosphorus in the $\mathrm{n}$ th sediment layer

$\phi_{n} V_{n} \frac{\mathrm{d} C_{D_{n}}}{\mathrm{~d} t}=\phi_{n-1, n} v_{s_{n-1}}\left(\alpha_{n-1, n} C_{D_{n-1}}\right.$

sedimentation from upper layer

$$
\begin{gathered}
\left.+\beta_{n-1, n} C_{D_{n}}\right) A_{n-1, n}-\phi_{n, n+1} v_{s_{n}}\left(\alpha_{n, n+1} C_{D_{n}}\right. \\
\text { sedimentation to lower layer }
\end{gathered}
$$

$$
\begin{aligned}
& \left.+\beta_{n, n+1} C_{D_{n+1}}\right) A_{n, n+1}+\frac{\Phi_{n-1, n} D A_{n-1, n}}{L_{n-1, n}} \\
& \text { diffusion } \\
& \times\left(C_{D_{n}}-C_{D_{n-1}}\right)+\frac{\phi_{n, n+1} D A_{n, n+1}}{L_{n, n+1}}\left(C_{D_{n+1}}-C_{D_{n}}\right)
\end{aligned}
$$$$
\text { diffusion }
$$

$$
+\mu_{3} C_{P_{n}} V_{n}
$$

$$
\text { reaction }
$$

The equations with associated descripters are essentially self explanatory. The equation notation is listed in Table 1. The first term on the right hand side of the Eqn. (6) for the first sediment layer is the loading from the hypolimnion. In Eqns. (6) and (7), the $\alpha$ and $\beta$ terms are finite difference weighting factors which determine the dissolved phosphorus concentration at the contact face between two adjacent segments (Thomann, 1972).

A variable-order variable-stepsize numerical scheme, developed by Krogh (1969) is used to solve the differential equations in the model. This routine adjusts stepsize and integration order as rates and error tolerances vary. This integration scheme has proven efficient and simple to use.

\section{MODEL PARAMETER EVALUATION}

There are a number of ways to obtain the parameter and coefficient values for the model cali- bration. In this study, field data from White Lake were used extensively to evaluate the coefficients defined in the model formulation. Wherever the data were not available, the literature was consulted to provide a range of values for the parameter. Only a brief description of the parameter determination procedure is present herein because a detailed description can be found in Lung (1975).

The vertical eddy diffusion coefficient characterizing the seasonal variation of the vertical mixing between the epilimnion and the hypolimnion was calculated by the flux-gradient method (Jassby \& Powerll, 1975) using temperature data (Fig. 3). The time variable equivalent linear kinetic coefficients $\mu_{1}$ and $\mu_{2}$ (shown in Fig. 4) were determined by a biological production model (Canale et al., 1974) which considers non-linear interactions of light, temperature, and nutrient levels. Since no field data were available for the estimation of the settling velocity of the particulate phosphorus, a range of $0.3 \mathrm{~m} /$ day to $0.5 \mathrm{~m} /$ day was selected from Burns \& Pashley (1974).

The diffusion coeffient in the interstitial water was estimated to be $2 \times 10^{-6} \mathrm{~cm}^{2} / \mathrm{sec}$ from historical records of lake chloride concentrations and sediment profiles in White Lake. The kinetic coefficient $\mu_{3}$, which describes the transformation of phosphorus from the particulate form to the soluble form in the upper sediment, was obtained by model tuning to match the observed phosphorus profiles in the sediment and is shown in Fig. 4. It is found that $\mu_{3}$ varies seasonably and inversely to the dissolved oxygen content of the hypolimnion.

The above model parameters and coefficients (Figs. 3 and 4) together with the phosphorus loading rates

\begin{tabular}{|c|c|c|}
\hline Symbol & Description & Units \\
\hline $\begin{array}{l}A_{1,2}, A_{2,3}, ., A_{n-1, n} \\
\alpha_{1,2}, \alpha_{2,3}, ., \alpha_{n-1, n} \\
\beta_{1,2}, \beta_{2,3}, ., \beta_{n-1, n}= \\
C_{P_{1}}, C_{P_{2}}, \ldots, C_{P_{n}} \\
C_{D_{1}}, C_{D_{2}}, ., C_{D_{n}} \\
D \\
K \\
L_{1,2}, L_{2,3}, ., L_{n-1, n} \\
P_{1} \\
Q \\
\mu_{1} \\
\mu_{2} \\
\mu_{3} \\
V_{1}, V_{2}, \ldots, V_{n} \\
v_{s_{1}}, v_{s_{2}}, \ldots, V_{s_{n}} \\
v_{s s} \\
W_{P}, W_{D} \\
X_{P 1}\end{array}$ & $\begin{array}{l}\text { contact area between segments } \\
\text { weighting factor } \\
1-\alpha \\
\text { concentration of particulate phosphorus } \\
\text { concentration of dissolved phosphorus } \\
\text { diffusion coefficient in the sediment } \\
\text { vertical eddy diffusion coefficient } \\
\text { average depth of segments } \\
\text { density of solid particles in top sediment layer } \\
\text { tributary flow into epilimnion } \\
\text { first-order kinetic coefficient in the epilimnion } \\
\text { first-order kinetic coefficient in the hypolimnion } \\
\text { first-order kinetic coefficient in the sediment } \\
\text { volume of segment } \\
\text { settling velocity or sedimentation rate } \\
\text { accumulation rate at the sediment-water interface } \\
\text { loadings } \\
\text { fraction of phosphorus solid particles }\end{array}$ & $\begin{array}{l}\mathrm{m}^{2} \\
\text { dimensionless } \\
\text { dimensionless } \\
\mathrm{gmP} / \mathrm{m}^{3} \\
\mathrm{gmP} / \mathrm{m}^{3} \\
\mathrm{~m}^{2} / \mathrm{day} \\
\mathrm{m}^{2} / \mathrm{day} \\
\mathrm{m} \\
\mathrm{gmdw}^{3} \mathrm{~m}^{3} \\
\mathrm{~m}^{3} / \mathrm{day} \\
\mathrm{day}-1 \\
\mathrm{day}-1 \\
\mathrm{day}-1 \\
\mathrm{~m}^{3} \\
\mathrm{~m} / \mathrm{day} \\
\mathrm{m} / \mathrm{day} \\
\mathrm{gmP} / \mathrm{day} \\
\mathrm{mgP} / \mathrm{mgdw}\end{array}$ \\
\hline
\end{tabular}
(see Fig. 5) represent the necessary input data for the model.

The parameters and coefficients used in model calibration are summarized in Table 2. Also included are values wherever available from other studies. The

Table 1. Equation notation 


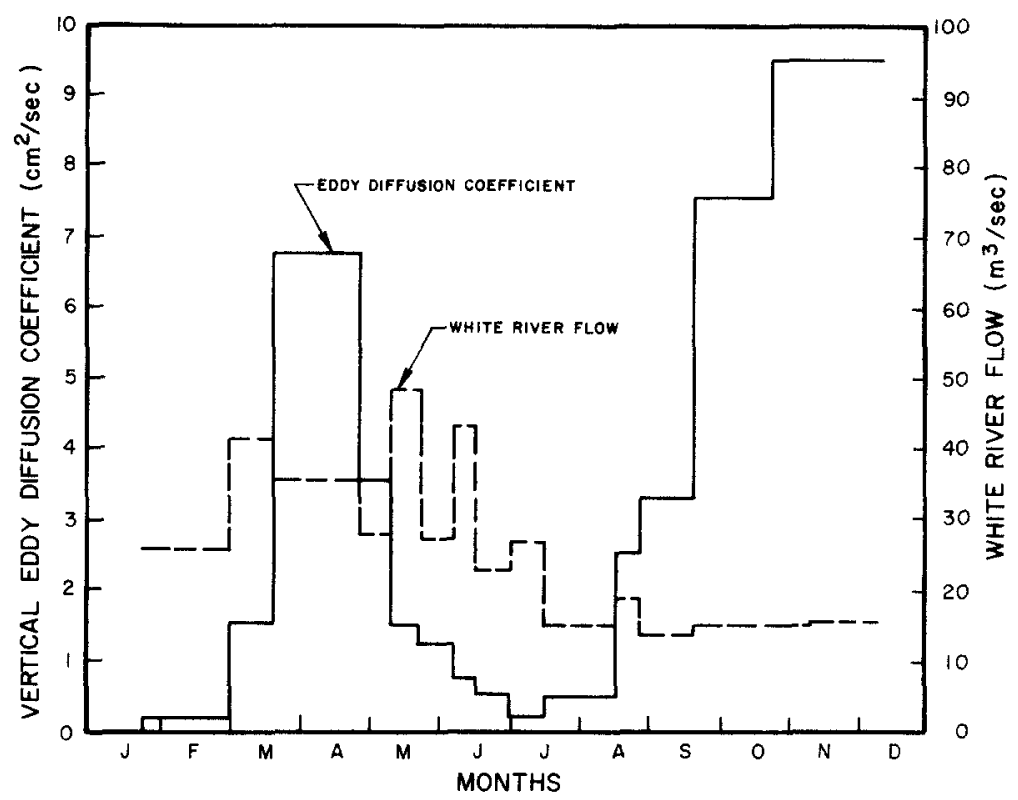

Fig. 3. Eddy diffusion coefficient and White River flow.
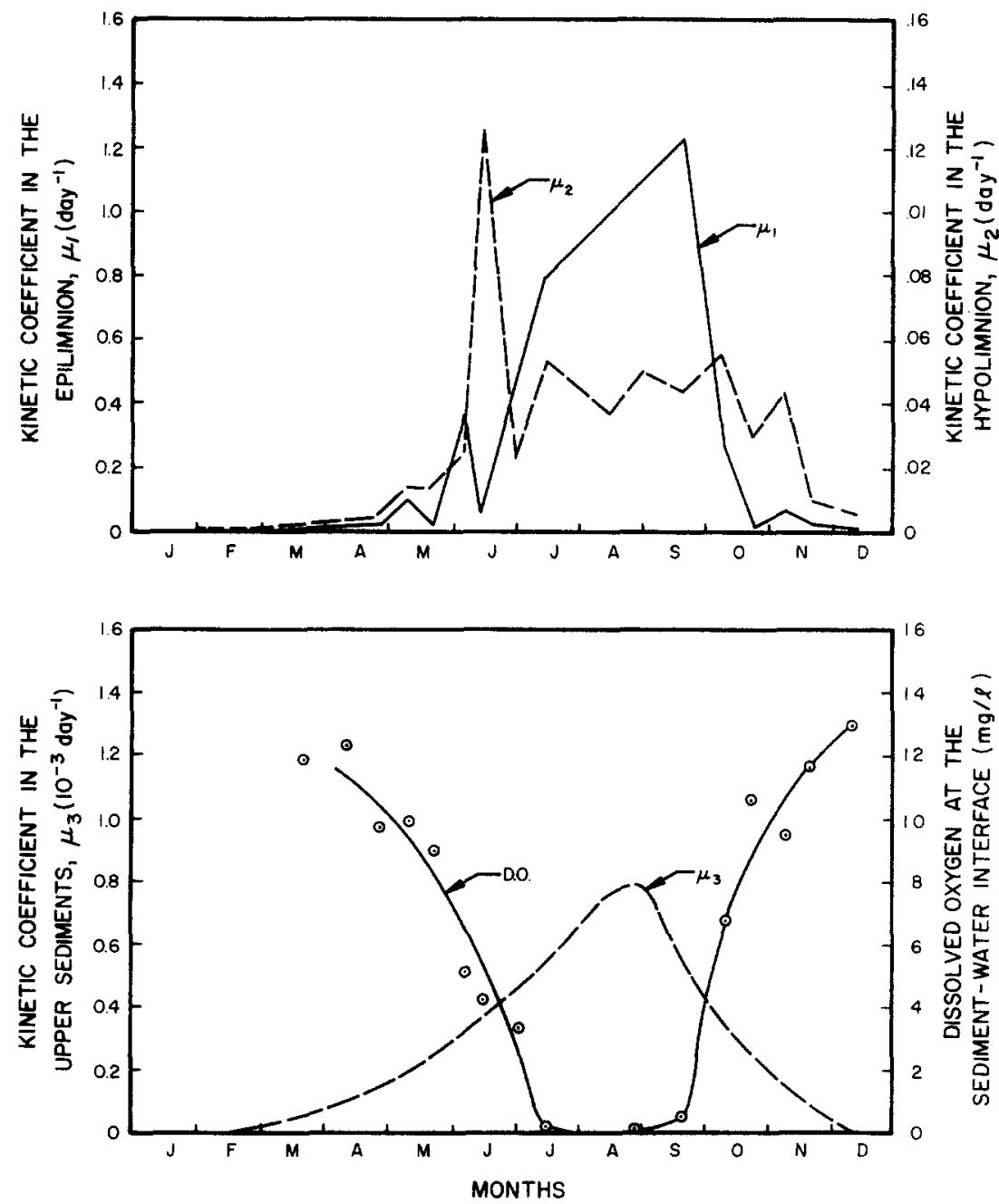

Fig. 4. Variations of kinetic coefficients in water and upper sediment and of dissolved oxygen concentration of the sediment-water interface. 


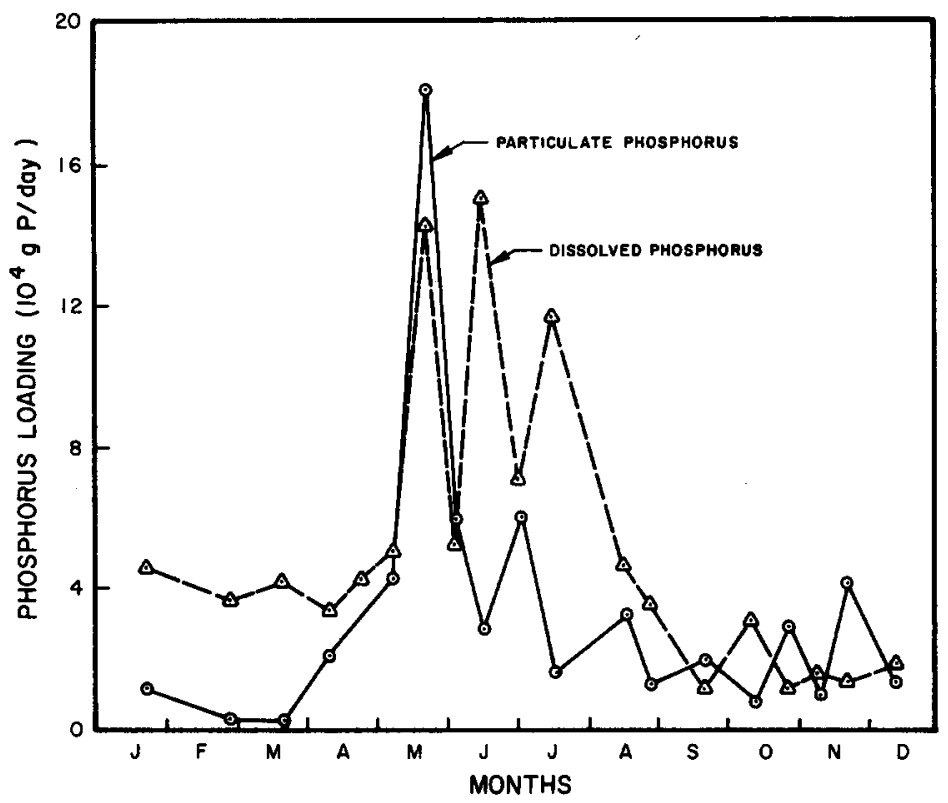

Fig. 5. Phosphorus loading rates from White River, 1974.

comparison indicates that the parameter values used in this study are reasonably close to the reported values.

\section{MODEL CALIBRATION}

The results of model calibration using the 1974 data are shown in Figs. 6 and 7. The agreement between the model calculations and observed data is good although some data deviate from the model calculations. In the epilimnion, the model predicts lower concentrations of dissolved phosphorus than those observed, especially during the summer months. The reason for this descrepancy is complex, but is essentially based on the fact that summer values of the kinetic coefficient in the epilimnion may be overestimated. This is because total dissolved phosphorus is used in the phytoplankton uptake component of the model instead of biologically available reactive phosphorus. It is probable that the phosphorus which is available for algal growth is only a small protion of the total dissolved phosphorus in the summer. Since the model assumes that all dissolved phosphorus is available for algal growth, differences between the data and model calculation are not unexpected. The model gives better results during the winter because of the high ratio of soluble reactive phosphorus to total soluble phosphorus.

The differences between the calculated and observed concentrations of particulate phosphorus in the epilimnion may be caused by use of constant settling velocities in the lake. In fact, slower settling is expected in spring due to lower temperatures in the lake and the favorable nutritional state of the algae. Another suggested reason for this result is that the overall settling velocity in the model may be too high. This question is explored later in the sensitivity analysis.

In the interstitial waters, the calculated dissolved phosphorus concentrations approximately match the observed profiles (Fig. 7). The model predicts fairly well the phosphorus dynamics in the upper layers of the sediment. This result is very encouraging because the upper layers of the sediment are the highly crucial regions which regulate the phosphorus equilibrium between the sediment and the

Table 2. Model parameters and coefficients

\begin{tabular}{|c|c|c|c|}
\hline Parameter & Unit & Value & Reference \\
\hline \multirow[t]{3}{*}{$v_{s}$ settling velocity } & $\mathrm{m} /$ day & $0.3-0.5$ & this study \\
\hline & & $0.1-0.4$ & Imboden (1974) \\
\hline & & $0.1-0.27$ & Snodgrass \& O’Melia (1975) \\
\hline \multirow{3}{*}{$\begin{array}{l}\mu_{1} \text { kinetic coefficient of } \\
\text { photosynthesis }\end{array}$} & day $^{-1}$ & $0.01-1.2$ & this study \\
\hline & & $0.06-2.0$ & Imboden (1974) \\
\hline & & $0.06-2.0$ & Snodgrass \& O'Melia (1975) \\
\hline \multirow{3}{*}{$\begin{array}{l}\mu_{2} \text { kinetic coefficient of } \\
\text { mineralization }\end{array}$} & day $^{-1}$ & $0.001-0.12$ & this study \\
\hline & & $0.003-0.02$ & Imboden (1974) \\
\hline & & 0.03 & Snodgrass \& O'Melia (1975) \\
\hline $\begin{array}{l}\mu_{3} \text { kinetic coefficient in the } \\
\text { upper sediment }\end{array}$ & $\mathrm{day}^{-1}$ & $0.0001-0.0008$ & this study \\
\hline$\mu_{4}$ kinetic coefficient in the & day $^{-1}$ & 0.00002 & this study \\
\hline lower sediment & & 0.000032 & Stumm \& Leckie (1971) \\
\hline $\begin{array}{l}K \text { eddy diffusion } \\
\text { coefficient }\end{array}$ & $\mathrm{cm}^{2} / \mathrm{sec}$ & $0.3-9.5$ & this study \\
\hline $\begin{array}{l}D \text { diffusion coefficient in the } \\
\text { interstitial water }\end{array}$ & $\mathrm{cm}^{2} / \mathrm{sec}$ & $2 \times 10^{-6}$ & this study \\
\hline
\end{tabular}


overlying water. The particulate phosphorus associated with the solid particles decreases slightly in the upper layers over the year.

In order to further evaluate the adequacy of the model, a number of model mechanisms have been examined which provide additional insight into the behavior of the system. Seasonal variations of the kinetic transformation terms in the lake shown in Fig. 8. The conversion rate of phosphorus in the epilimnion reaches a maximum value of $3.8 \mu \mathrm{g} \mathrm{P} / 1 /$ day in summer. At the same time, the maximum conversion rate in the hypolimnion reaches $0.55 \mu \mathrm{g} / \mathrm{P} / \mathrm{l} /$ day. These values are close to those reported by Stumm \& Leckie (1971) for a hypothetical lake. Variations of phosphorus regeneration from the sediment and of particulate phosphorus sedimentation from the hypolimnion are also shown in Fig. 8. It is seen that the kinetic and settling terms in the model are the important factors in the system.

Interactions in the upper layers of the sediment are shown in Fig. 9. The results indicate that release of dissolved phosphorus from the particulate phosphorus in the first sediment layer is not sufficient to support diffusion across the sediment-water interface. Migration of the dissolved phosphorus from the lower sediment due to diffusion provides a significant flux to the upper sediment. This phenomenon has also been described by Williams \& Mayer (1972).

When the settling of the particulate matter is not included, the model predicts continuous accumulation of the particulate phosphorus in the epilimnion after the spring bloom of algae (Fig. 10). The particulate phosphorus level in the hypolimnion does not increase significantly until after the fall overturn in September when the water column is fully mixed. In general, with no settling, the particulate phosphorus level in White Lake is almost double the observed level. Only slight variation of the dissolved phosphorus is predicted by the model if sedimentation is neglected. Higher concentrations of dissolved phosphorus in the hypolimnion late in the year are due to increased conversion of dissolved phosphorus from the particulate phosphorus. The fall overturn helps increase the dissolved phosphorus level in the epilimnion by transporting phosphorus from the hypolimnion (Fig. 10).

If regeneration of phosphorus from the sediment is eliminated. the model predicts a much lower dissolved phosphorus level in the hypolimnion during the summer months (Fig. 10). Other phosphorus components are affected only slightly. Although the dissolved phosphorus level in the hypolimnion drops by one-third in the summer if regeneration is neglected the dissolved phosphorus level in the epilimnion is virtually unaffected in the summer because of a limited exchange across the thermocline. The low concentrations of dissolved phosphorus in the epilimnion after the fall overturn are due to the low concentrations in the hypolimnion.

The above discussion indicates the importance of settling and sediment regeneration of phosphorus in White Lake Regeneration from the sediment accounts for almost onethird of the dissolved phosphorus in the hypolimnion. The results also suggest that more than one phosphorus component in each segment of the model is necessary to insure proper simulation of phosphorus dynamics in this system As discussed earlier, sufficient insight concerning the phos-

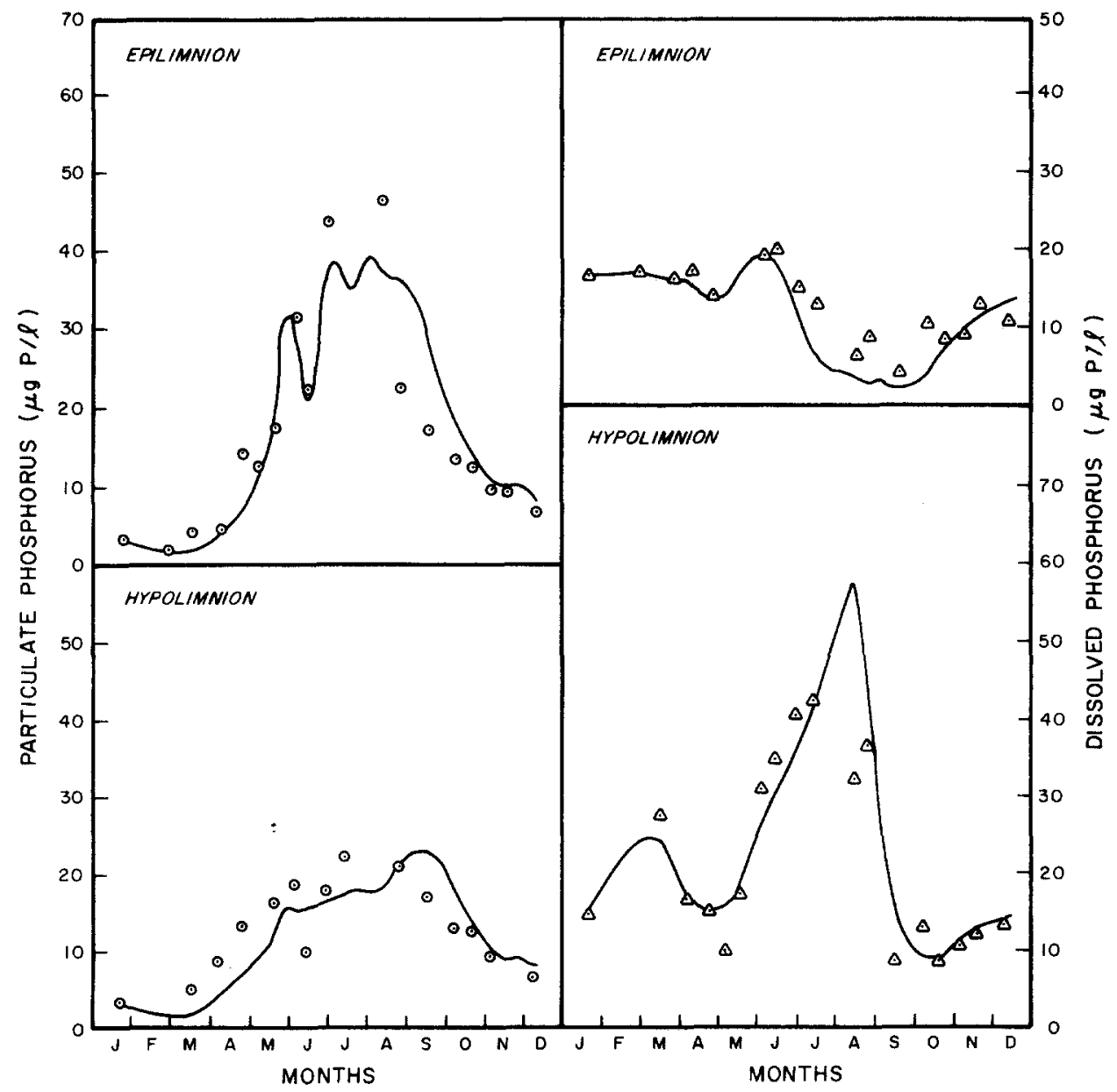

Fig. 6. Particulate and dissolved phosphorus in White Lake; comparison of model calculations and observed data, 1974. 

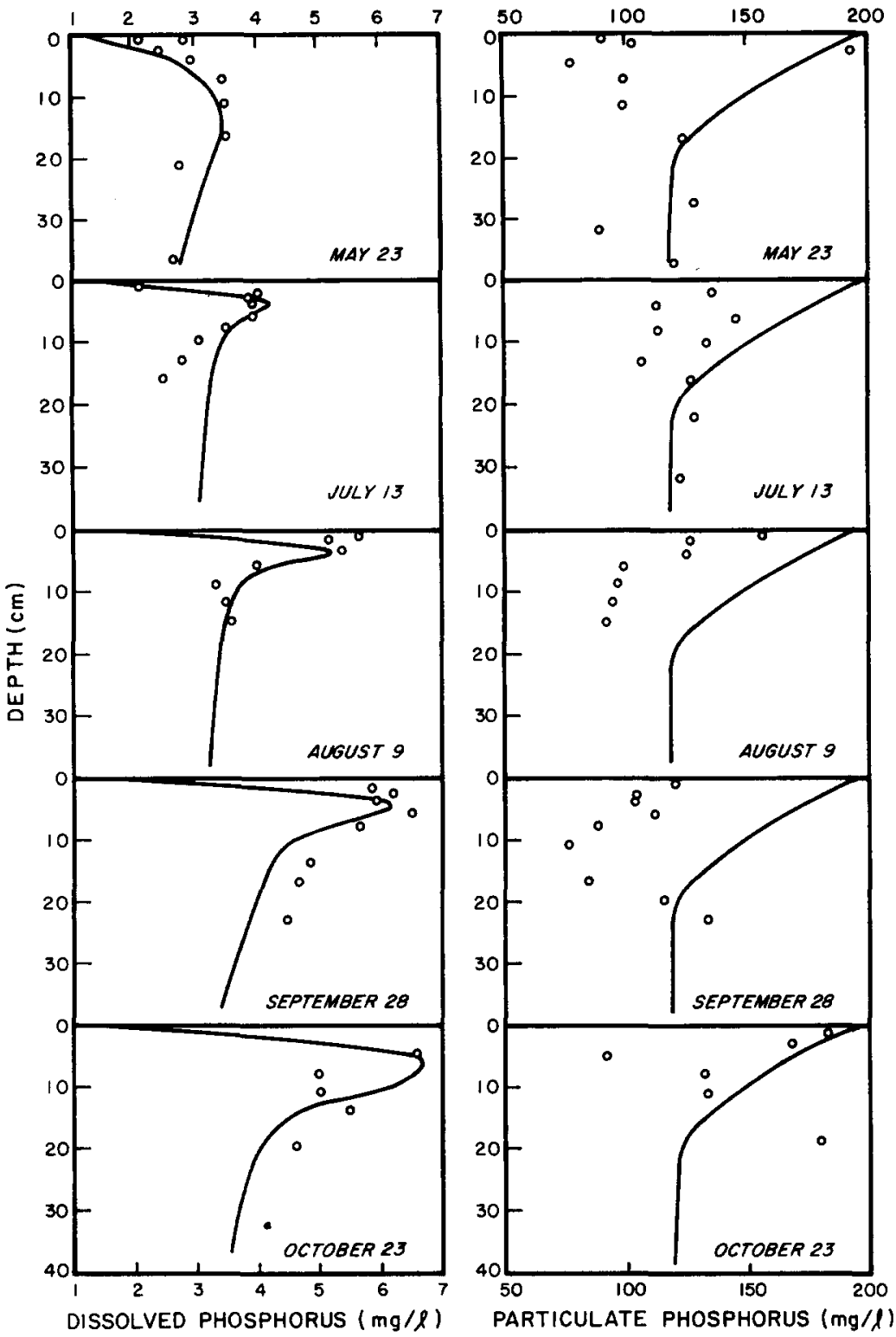

Fig. 7. Phosphorus in White Lake sediments; comparison of model calculations and observed data,

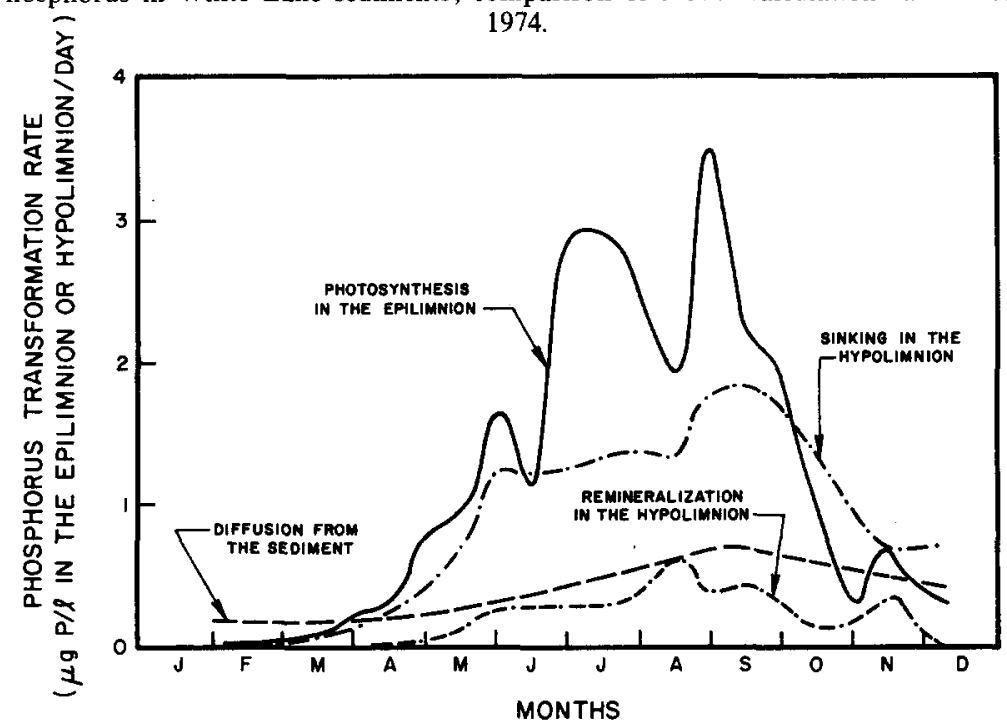

Fig. 8. Phosphorus conversion rates in White Lake, 1974. 


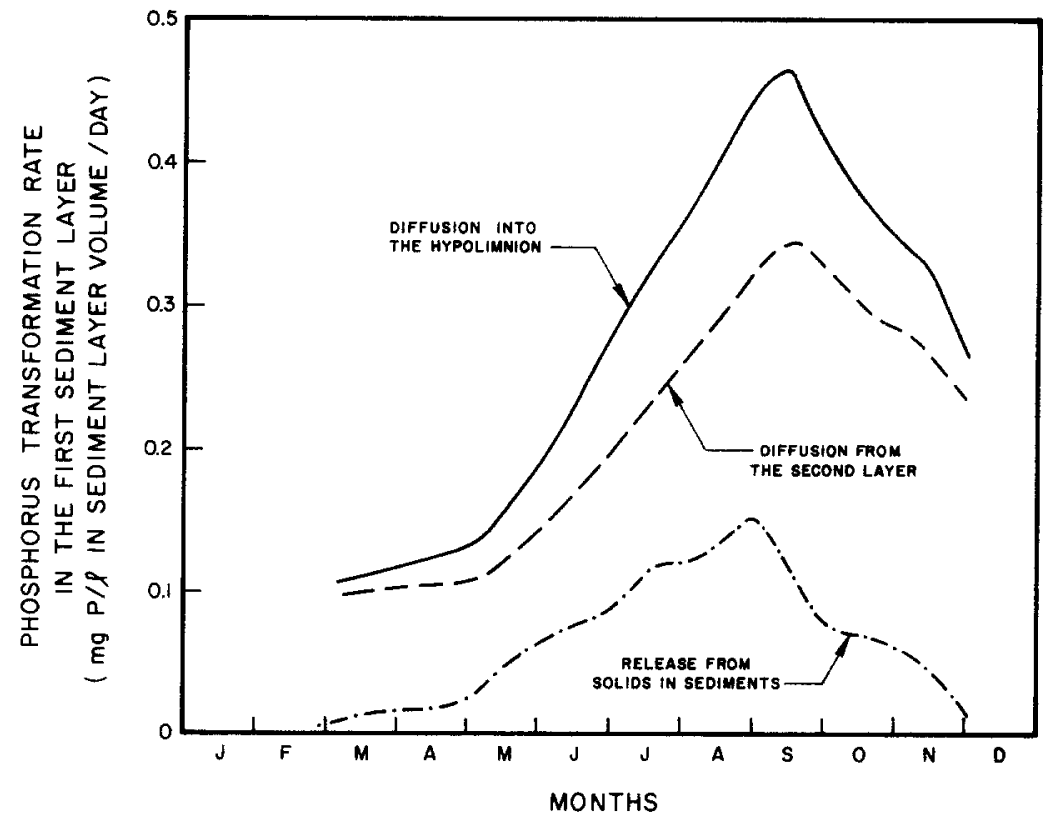

Fig. 9. Phosphorus interactions in White Lake sediment, 1974.

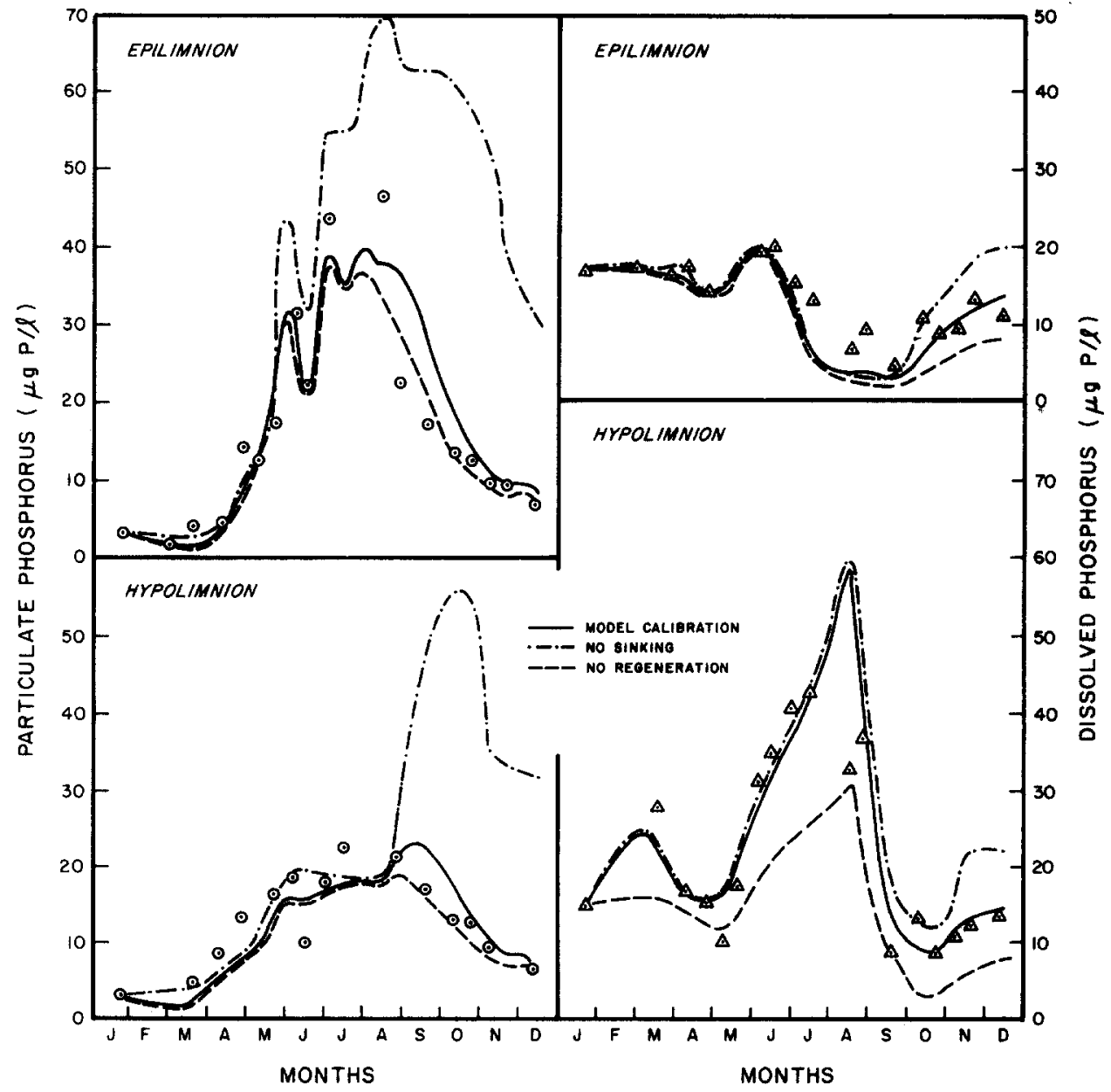

Fig. 10. Effects of sinking and regeneration from the sediments on the phosphorus levels in White Lake, 1974. 
phorus dynamics such as provided by the above results cannot be obtained by modeling the total phosphorus as a single component.

\section{SENSITIVITY ANALYSIS}

A sensitivity analysis for the diffusion coefficient in the interstitial water and the settling velocity in the overlying water has been performed to provide further understanding of the model. Using porosity data for White Lake sediments, a range of diffusion coefficients $\left(2 \times 10^{-7} \mathrm{~cm}^{2} / \mathrm{sec}-10^{-5} \mathrm{~cm}^{2} / \mathrm{sec}\right)$ was derived for the sensitivity analysis. The relationship between the diffusion coefficient and the porosity compiled by Manheim (1970) is used for this derivation. The results show that increasing or decreasing the diffusion coefficient significantly changes the dissolved phosphorus concentration in the hypolimnion and slightly alternates the distribution of other phosphorus components in the lake (Fig. 11). It should be noted that the dissolved phosphorus concentration in the epilimnion is not sensitive to the variation of this diffusion coefficient in summer when the vertical mixing in the lake is prohibited by stratification.
Another important parameter in the model is the settling velocity of the particulate phosphorus. It is well known that dead phytoplankton cells sink slowly in the water. An average settling velocity of $0.1 \mathrm{~m} /$ day for phytoplankton has been generally reported (Smayda, 1970) and is therefore, selected as the lower bound for the sinking of the particulate phosphorus in the epilimnion for this study. Similarly, a rate of $0.3 \mathrm{~m} /$ day in the hypolimnion is assumed. The upper bounds used in this analysis $(0.5$ and $0.7 \mathrm{~m} /$ day) in the epilimnion and the hypolimnion respectively are derived from Burns \& Pashley (1974). The model simulations show a small effect of the variation of the settling velocity on the dissolved phosphorus concentrations in White Lake. The lower bounds actually give a somewhat better fit for the particulate phosphorus in the epilimnion than the velocities used in the model calibration.

\section{MODEL VERIFICATION}

The above presentation of model calibration, model testing, and sensitivity analysis has strongly indicated that the model is properly tuned. The model can be

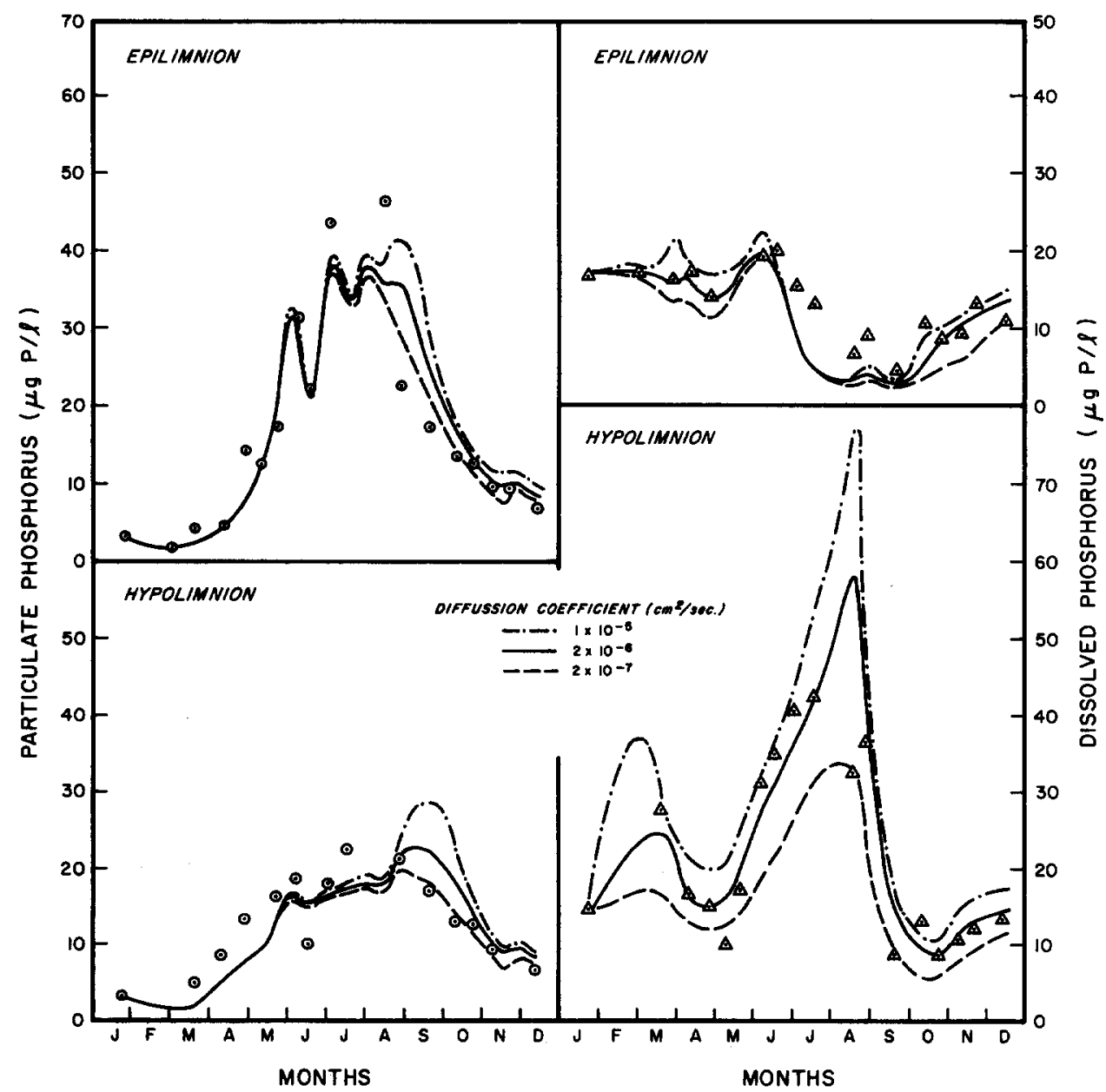

Fig. 11. Sensitivity analysis of phosphorus levels in White Lake to diffusion coefficient in the sediment. 
verified by comparing the model calculations with the 1973 data from White Lake which were not used in determining the model parameters. Significant changes in the White River flow (from $16.9 \mathrm{~m}^{3} / \mathrm{sec}$ in $1973-23.2 \mathrm{~m}^{3} / \mathrm{sec}$ in 1974 ) is enough to make this run an independent verification for the model. Although there was a significant difference in the flow between these 2 years, only a slight change in the phosphorus loading rate is observed as a result of flow increase and sewage diversion in 1974 (Lung, 1975).

Good agreement between the model calculations and observed data is shown in Fig. 13. The model performs satisfactorily and accounts for growth in the epilimnion and the sediment release in the hypolimnion. The settling velocities used in this run are 0.1 in the epilimnion and 0.3 in the hypolimnion which are different from the calibration values but are within the range of the sensitivity analysis (see Fig. 12). This change in settling velocity may be justifiable considering the fact that the settling process depends on the environmental conditions such as wind, temperature, and flow patterns in the lake which vary from year to year.

\section{CONCLUSIONS}

Because phosphorus is involved in many biochemical reactions and transformations, it is necessary to separate phosphorus into different operational forms in order to obtain detailed insight into the dynamics of phosphorus cycling in lakes. This situation is well demonstrated in White Lake where interactions between sediments and overlying waters play an important role in regulating the phosphorus level. Previous models which consider total phosphorus as the lone variable have been less successful when applied to eutrophic lakes. It appears that the model developed and verified in this study works well for White Lake.

Sediment regeneration of phosphorus has been found important in White Lake, especially during the summer anaerobic periods. The kinetic coefficient in the upper sediment layers has been found to correlate with the dissolved oxygen level at the bottom of the lake. The model structure developed in this study should be directly coupled to a model for dissolved oxygen in the hypolimnion. This will permit an interactive calculation of the solubilization of phosphorus in the upper sediments.

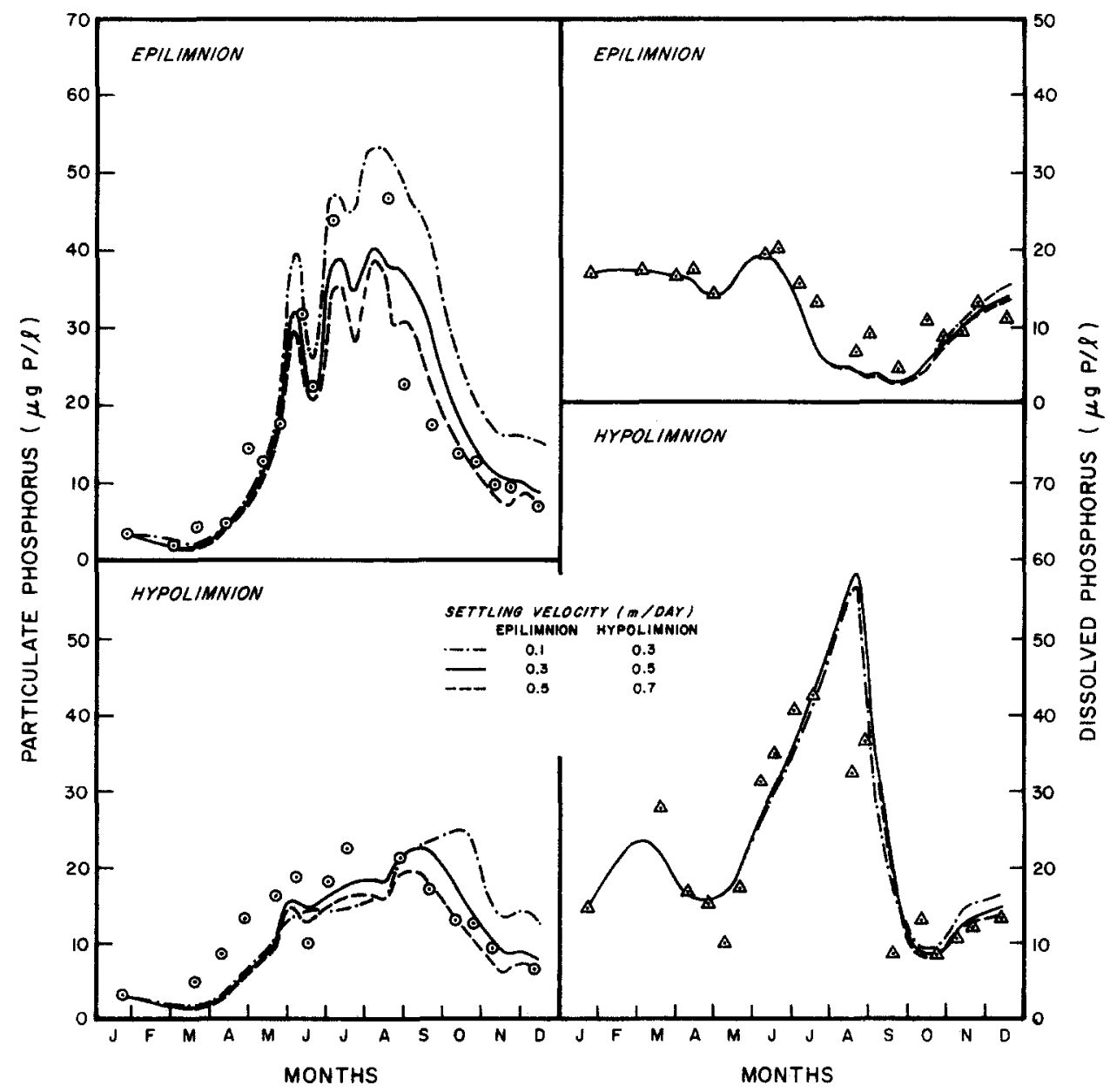

Fig. 12. Sensitivity analysis of phosphorus levels in White Lake to sinking velocity in the water. 


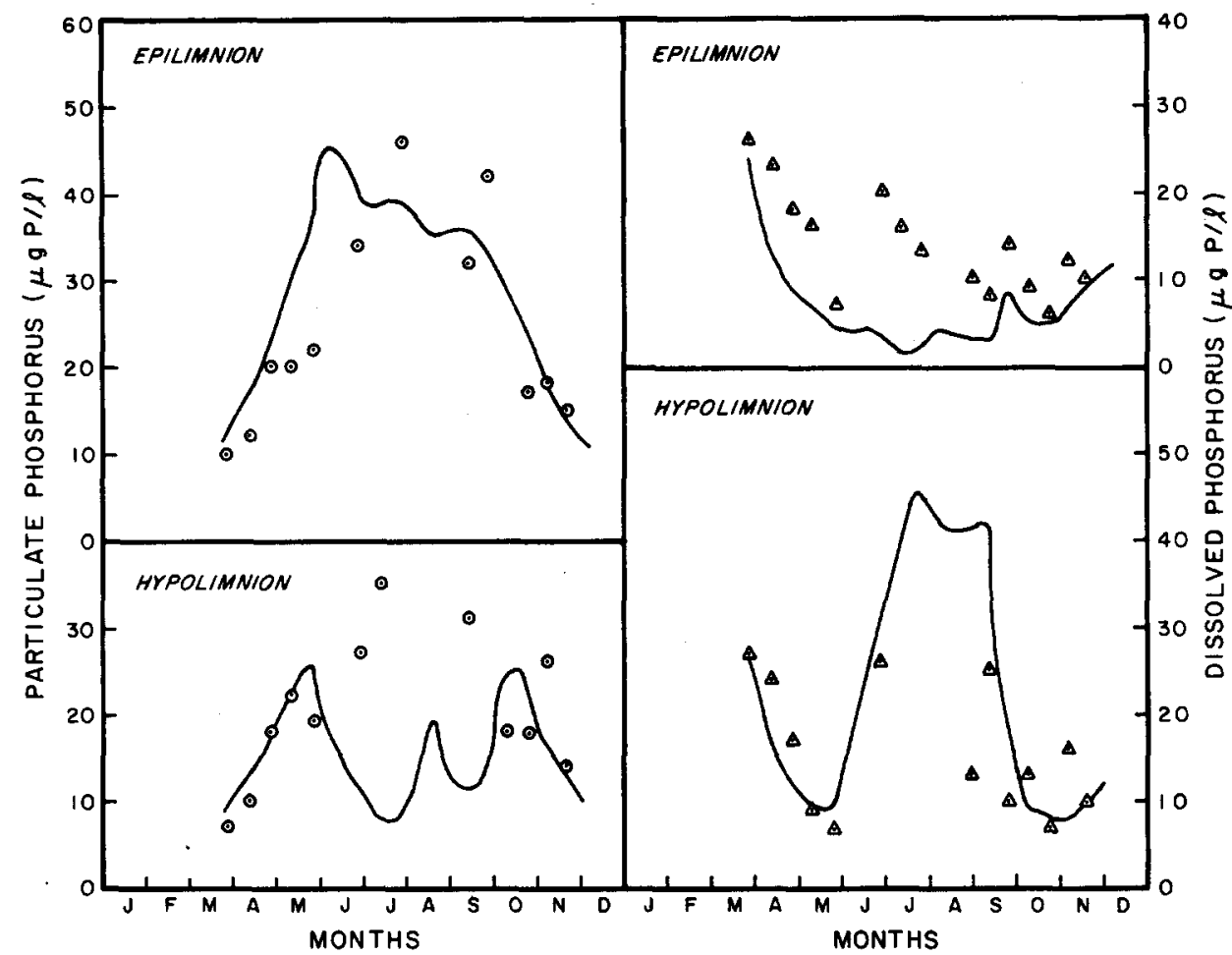

Fig. 13. Model verification-comparison of model calculations and observed data (1973).

Treatment of the moving sediment-water interface by introducing the sedimentation term has proved successful. The water system and the sediment system can be coupled together both numerically and physically. The model, therefore, is able to handle the interactions between sediments and water satisfactorily.

Acknowledgements-The research reported in this paper is the direct result of a grant from Region $V$ of the U.S Environments Protection Agency-Grant Number G-00-5104. Appreciation is also extended to the University of Michigan Sea Grant Program which has supported work by Dr. Canale on this and a number of other related modeling projects over the past several years.

\section{REFERENCES}

Bortleson G. C. (1970) Use of lake sediment cores to estimate eutrophication. Ph.D. Thesis, University of Wisconsin.

Burns N. M. \& Pashley A. E. (1974) In situ measurement of the settling velocity profile of particulate organic carbon in Lake Ontario. J. Fish. Res. Bd Can. 31, 291-297.

Canale R. P., Hineman D. F. H. \& Nachiappan S. (1974) A biological production model for Grand Traverse Bay. Sea Grant Tech. Report No. 37, University of Michigan, pp. 116.

Chiaken E. I., Poloncsik S. \& Wilson C. D. (1973) Muskegon sprays sewage effluents on lands. Civ. Engng. May 1973, 49-53.

Dillon P. J. \& Rigler F. H. (1974) A test of simple nutrient budget model predicting the phosphorus concentration in lake water. J. Fish. Res. Bd Can. 31, 1771-1778.

Fillos J. \& Biswas H. (1976) Phosphate release and sorption by Lake Mohegan sediments. Proc. Am. Soc. Civil Engrs, J. envir. Eng. Div. 102, 239-249.

Fillos J. \& Swanson W. R. (1975) The release rate of nutrients from river and lake sediments. $J$. Water Poll. Cont. Fed. 47, 1032-1042.
Imboden D. M. (1974) Phosphorus model of lake eutrophication. Limnol. Oceanogr. 19, 297-304.

Jassby A. \& Powell T. (1975) Vertical patterns of eddy diffusion during stratification in Castle Lake, California. Limnol. Oceanogr. 20, 530-543.

Krogh F. T. (1969) VODQ/SVDQ, DVDQ-variable order intergrators for the numerical solution of ordinary differential equations. TV Document No. CP-2308, NOP-11643 JPL, Pasadena, California.

Lorenzen M. W., Smith D. J. \& Kimmel L. V. (1976) A long term phosphorus model for lakes. Application to Lake Washington. In: Modeling the Biochemical Processes in Aquatic Ecosystems, 75-91, (Edited by R. P. Canale), Ann Arbor Science Publishers, Michigan.

Lorenzen M. W. (1973) Predicting the effects of nutrient diversion on lake recovery. In: Modeling the Eutrophication Process, 205-210, (Edited by E. J. Middlebrooks, D. H. Faldenborg \& T. E. Maloney), Ann Arbor Science Publishers, Michigan.

Lung W. S. (1975) Modeling of phosphorus sedimentwater interactions in White Lake, Michigan. Ph.D Thesis, University of Michigan.

Manheim F. T. (1970) The diffusion of ions in unconsolidated sediments. Earth Planet Sci. Lett. 9, 307-309.

Mortimer C. H. (1941) The exchange of dissolved substances between mud and water in lakes I and II. $J$. Ecol. 29, 280-329.

Mortimer C. H. (1942) The exchange of dissolved substances between mud and water in lakes III and IV. J. Ecol. 30, 147-201.

Snodgrass W. J. \& O'Melia C. R. (1975) Predictive model for phosphorus in lakes. Envir. Sci. Tech. 9, 937-944.

Smayda T. J. (1970) The suspension and sinking of phytoplankton in the sea. Oceanogr. Mar. Biol. Ann. Rev. 8, 353-414.

Spear R. D. (1970) Leaching of phosphorus from lakes sediments. Ph.D. Thesis, University of Wisconsin.

Sridharan L. (1970) Aqueous environmental chemistry of phosphorus in lower Green Bay. Ph.D. Thesis, University of Wisconsin. 
Stumm W. \& Leckie J. O. (1971) Phosphate exchange with sediments: its role in the productivity of surface waters. In: Advances in Water Pollution Research, Vol. 2, III-27/1-16, (Edited by S. H. Jenkins). Pergamon Press, Oxford

Thomann R. V. (1972) System Analysis and Water Quality Management, Environmental Research and Applications, Inc. pp. 286.

Vollenweider R. A. (1969) Possibilities and limits of ele- mentary models concerning the budget of substances in lakes. Archs Hydrolobiol. 66, 1-36.

Vollenweider R. A. (1975) Input-output models. Schweiz. Z. Hydrol. 37, 53-84.

Williams J. D. H. \& Mayer T. (1972) Effects of sediment diagenesis and regeneration of phosphorus with special reference to lakes Erie and Ontario. In: Nutrients in Natural Waters, 281-315 (Edited by H. E. Allen \& J. R. Kramer). John Wiley. New York 